\title{
STUDY OF INTERHEMISPHERIC COHERENCE ON HEALTHY ADULTS
}

\author{
Mario Silva Jorge1, Ricardo Vieira Botelho², Antonio Carlos de Paiva Melo ${ }^{3}$
}

\begin{abstract}
The interhemispheric coherence of electroencephalogram was studied in a group of healthy individuals in the age range of 20-50 years. The results showed higher coherence for all bands in parietal regions (P3-P4). It was observed that individuals with high values of coherence for a certain frequency band in a pair of electrodes also showed high values of coherence for other bands across other pairs of electrodes. No significant influence on interhemispheric coherence was found for age, gender or hand dominance.
\end{abstract}

KEY WORDS: coherence, adults, EEG quantitative, normal pattern.

\begin{abstract}
Estudo da coerência interhemisférica em adultos normais
RESUMO - A coerência inter-hemisférica do eletrencefalograma foi estudada em uma população de indivíduos normais, na faixa etária de 20 a 50 anos. Os resultados mostraram maior valor de coerência para todas as bandas nas regiões parietais(P3-P4). Foi observado que em indivíduos com alto valor de coerência para determinada banda em um determinado par de eletrodos, também apresentam alto valor de coerência para outras bandas nos outros pares de eletrodos. Não foi observada influência da idade, sexo ou dominância manual no valor da coerência inter-hemisférica.
\end{abstract}

PALAVRAS-CHAVE: coerência, adulto, EEG quantitativo, padrões de referência.

EEG coherence allows correlation between different brain areas to be ascertained by analyzing the mutual relationship between two EEG signals across different frequency bands. As this constitutes a normalized value for the power of a given frequency, it is independent from signal amplitude oscillations ${ }^{1,2}$ Such a property makes coherence a relatively safe method for comparing groups of individuals in as far as differences in EEG powers do not impact estimated coherence values ${ }^{3}$. Reduced coherence between two regions is probably indicative of their decreased functional correlations. Ordinary coherence can be calculated between two cerebral electrodes, whether they be placed in the same hemisphere or in homologous areas, by means of a mathematical formula dividing the cross spectrum of these two channels by the product of self spectrum for each of these channels, as illustrated in the formula below:

$$
\operatorname{Co}(f) 2=\frac{[G x y(f)] 2}{G x x(f) G y y(f)}
$$

Co denotes coherence function, Gxx and Gyy are spectrum powers for each channel and Gxy is the power of cross-spectrum
The Co value between two electrodes ranges from 0 to 1 , where 1 denotes maximum correlation. When correlation is very low or null, the value approaches 0 . Thus, coherence represents a measure of cortical interconnectivity. Studies concerning coherence have shown that coherence between closely-placed electrodes is determined mainly by local connections excited by intracortical interneurons (Martinotti and short axoned stellate cells), whereas between distant electrodes such coherence is determined by long axonal connections ${ }^{4,5,6}$. These two compartments compete with one another, influencing the same neuronal population in an alternate manner.

The objective of the current investigation was to study the inter-hemispheric coherence between homologous areas in healthy individuals in the 20-50 year age bracket.

\section{METHOD}

A total of 190 tests were carried out on individuals with no neurological complaints, where subjects were submitted to digital EEG and then assessed. Subjects had no prior history of neurological problems such as traumatic brain injury, epilepsy, alcohol or drugs use and abuse, or clinical com-

Setor de Eletroencefalografia do Serviço de Neurologia do Hospital do Servidor Público Estadual, São Paulo SP, Brasil (HSPE): ${ }^{1}$ Médico responsável pelo setor de EEG quantitativo; ${ }^{2}$ Médico Assistente do Serviço de Neurocirurgia do HSPE; ${ }^{3}$ Diretor do Serviço de Neurologia do HSPE.

Received 15 September 2006, received in final form 16 January 2007. Accepted 21 February 2007. 
plaints. All subjects had previously undergone clinical and laboratory tests since they worked for the aeronautics industry which adopts strict medical examination on admission along with periodic check-ups. Laboratory assessment comprised full hemogram, ESR (erythrocyte sedimentation rate), fasting and post-prandial glycaemia, urea, creatinine, hepatic function and total cholesterol exams, as well as toxicological fractions, spirometric, audiologic and cardiologic assessments. Out of the 190 tests assessed, an initial sample of 82 subjects aged between 22 and 45 years was selected. Of these 82 individuals, 72 were included in the study while the remaining 10 were excluded due to undesirable events during signal acquisition or for not having presented the long wakeful periods needed to select the required epochs during any one state.

Of the 72 subjects studied, 63 were male and 9 female. None of the females were having their menstrual cycles. Age ranged from $21 \mathrm{y} 3 \mathrm{~m}$ to $48 \mathrm{y} 6 \mathrm{~m}$, with a mean of $34 \mathrm{y}$ $8 \mathrm{~m}$.

Twenty-five epochs were selected from each of these 72 exams, where epochs were 2.57 seconds long and in wake state. The chosen epochs then underwent fast Fourier transformation, thereby calculating the spectrum for each electrode, and subsequently coherence for electrode pairs.

The electrode placement scheme adopted was the 10$20 \%$ system in accordance with the International EEG Federation and the Brazilian Society of Clinical Neurophysiology (IFSNC-1974) 7-10. $^{\text {. }}$

The recording period was a minimum of 30 minutes while conforming to all other preconized conditions such as quiet environment, patient at rest, eyes closed.

During the exam, activation maneuvers were performed such as opening and closing of the eyes and hyperventilation. Intermittent photo stimulation was not carried out in any of the exams.

The equipment used was an Emsa 20-channel digital EEG with a sampling frequency of 200 samples per second and a digital analogue board with 12 byte processor.

Constant time employed was 0.3 seconds and epoch lengths set at 2.57 seconds, with $70 \mathrm{~Hz}$ high-frequency filter and $0.5 \mathrm{~Hz}$ for low frequencies.

Signal capture was carried out using concave $3 \mathrm{~mm}$-wide silver electrodes, placed on the scalp according to the 1020 international system using 22 electrodes (Fp1-Fp2, F7-F8, T3-T4, T5-T6, F3-F4, C3-C4, P3-P4, O1-O2, Fz, Cz, Pz, and Oz). Frequency bands were set up according to equipment capabilities as follows: delta 1 from 0 to $2 \mathrm{~Hz}$, delta 2 from 2.3 to $3.5 \mathrm{~Hz}$, theta 1 from 3.9 to $5.5 \mathrm{~Hz}$, theta 2 from 5.9 to 7.4 $\mathrm{Hz}$, alpha 1 from 7.8 to $9.8 \mathrm{~Hz}$, alpha 2 from 10.2 to $12.5 \mathrm{~Hz}$, beta 1 from 12.9 to $18 \mathrm{~Hz}$, beta 2 from 18.4 to $23.8 \mathrm{~Hz}$, beta 3 for frequencies greater than or equal to $24.2 \mathrm{~Hz}$.

The reference used was the linked ear reference assigned to electrodes $A 1$ and $A 2$, where electrode impedances were less than 5 kohms and pre-amplification greater than 100 mOhms.

This study was approved by the Research Ethics Committee of the Hospital do Servidor Publico Estadual-SP, São Paulo. All participants, or guardian relatives, signed in- formed consent terms prior to enrolment onto the present study.

Statistical analysis - Coherence values computed using readings from different electrode pairs were statistically compared using the Student t test with a $95 \%$ confidence level. Differences amongst coherence values in dextral and sinistral subjects were assessed using the Mann-Whitney Utest, while the Spearman test was employed for correlation between age and coherence for each frequency band. The statistical program utilized was the SPSS $11^{11-12}$.

Analysis for age, manual dominance and gender was based on F7 F8 coherence values only, in order to avoid excessive redundant data, given that previous analyses had shown high correlation between coherence values.

\section{RESULTS}

The results of the present study demonstrate a higher coherence value across all frequency bands and sub-bands in parietal regions (electrodes P3P4), showing a statistically significant difference on the Student t test ( $P$ ranging from 0.0014 to 0.0056 with a $95 \%$ significance level).

Tables 1, 2, and 3 show estimated mean using Hampel's M-Estimator method for inter-hemispheric coherence of subjects studied.

Figures 1 and 2 show that there are no relation in the coherence values between dextrals and sinistrals and its comportment related the age range.

Table 1. Inter-hemispheric coherence value for each frequency band and corresponding electrode pair.

\begin{tabular}{ccccc}
\hline & Delta & Theta & Alpha & Beta \\
\hline F3 F4 & 0.622 & 0.558 & 0.633 & 0.465 \\
C3 C4 & 0.669 & 0.583 & 0.561 & 0.462 \\
P3 P4 & 0.770 & 0.695 & 0.665 & 0.563 \\
O1 O2 & 0.712 & 0.626 & 0.637 & 0.544 \\
F7 F8 & 0.453 & 0.381 & 0.469 & 0.379 \\
T3 T4 & 0.491 & 0.376 & 0.411 & 0.377 \\
T5 T6 & 0.573 & 0.427 & 0.449 & 0.386 \\
\hline
\end{tabular}

Table 2. Inter-hemispheric coherence value for each electrode pair and frequency sub-band, at rest and with eyes closed.

\begin{tabular}{ccccc}
\hline & Delta 1 & Delta 2 & Theta 1 & Theta 2 \\
\hline F3-F4 & 0.652 & 0.593 & 0.544 & 0.572 \\
C3-C4 & 0.692 & 0.646 & 0.576 & 0.591 \\
P3-P4 & 0.792 & 0.749 & 0.693 & 0.697 \\
O1-O2 & 0.732 & 0.692 & 0.637 & 0.616 \\
F7-F8 & 0.502 & 0.405 & 0.372 & 0.391 \\
T3-T4 & 0.549 & 0.433 & 0.374 & 0.379 \\
T5-T6 & 0.622 & 0.524 & 0.432 & 0.423 \\
\hline
\end{tabular}


Table 3. Inter-hemispheric coherence value for each electrode pair and frequency sub-band, at rest and with eyes closed.

\begin{tabular}{cccccc}
\hline & Alpha 1 & Alpha 2 & Beta 1 & Beta 2 & Beta 3 \\
\hline F3-F4 & 0.676 & 0.59 & 0.474 & 0.482 & 0.44 \\
C3-C4 & 0.607 & 0.516 & 0.452 & 0.468 & 0.466 \\
P3-P4 & 0.694 & 0.637 & 0.55 & 0.557 & 0.583 \\
O1-O2 & 0.632 & 0.642 & 0.518 & 0.534 & 0.581 \\
F7-F8 & 0.482 & 0.456 & 0.366 & 0.402 & 0.369 \\
T3-T4 & 0.406 & 0.416 & 0.382 & 0.394 & 0.356 \\
T5-T6 & 0.448 & 0.451 & 0.365 & 0.389 & 0.406 \\
\hline
\end{tabular}

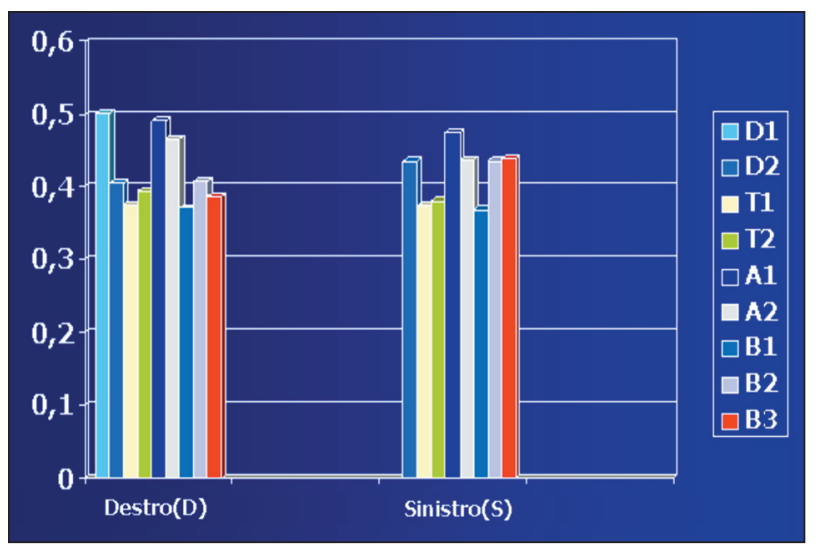

Fig 1. Coherence value for each frequency band at electrode pair F7F8, for dextral and sinistral subjects.

\section{DISCUSSION}

In the present study sample, the parietal region (electrodes P3 and P4) tended to present the highest inter-hemispheric Co value, for all frequency bands. However, this finding does not extend to all frequency sub-bands, for which higher values were found between P3 and P4 electrodes for delta 1 and 2, and theta 1 and 2 sub-bands (Table 2), and alpha 1 and beta 1, 2 and 3 (Table 3 ), whilst the alpha 2 sub-band presented the highest values in 01 and 02 . These data on inter-hemispheric $\mathrm{Co}_{\mathrm{O}}$ is in agreement with results found in the international literature investigated $^{13-14}$.

Thus, as standard and quantitative EEG show variation regarding chronological age, a number of studies have focused on assessing this relationship in coherence. Moreover, despite conflicting results, they show that alterations are different for each frequency band, such that in normal maturation there is an increase in coherence of fast bands, particularly alpha, with a reduction for slow bands ${ }^{13-16}$. Concerning the inter-hemispheric coherence value found in the present study for each age bracket of the sample, no significant differences were observed between the 20-29 year, 30-39 year, and 40-49 year age groups. For the 20-50 year age group, EEG spectral characteristics tend to change little, in contrast to both younger (under 10 years) and elderly (over 60 years) groups, according to previous studies in our setting ${ }^{17-18}$.

Marozi et al. ${ }^{19}$, in an evolutive study, found increased coherence in the frontal region across all bands, except beta, in a population of 46 students followed for 3 years. Aging causes a general reduction in coherence in all bands, consistent with shrunken corpus callosum, along with reduced neuronal population and white matter ${ }^{13-16}$.

The present study found no differences in interhemispheric coherence value in relation to manual dominance in this age bracket, akin to findings by Duffy et al. ${ }^{16}$ (U Mann-Whitney test with $\mathrm{p}<0.05$ ).

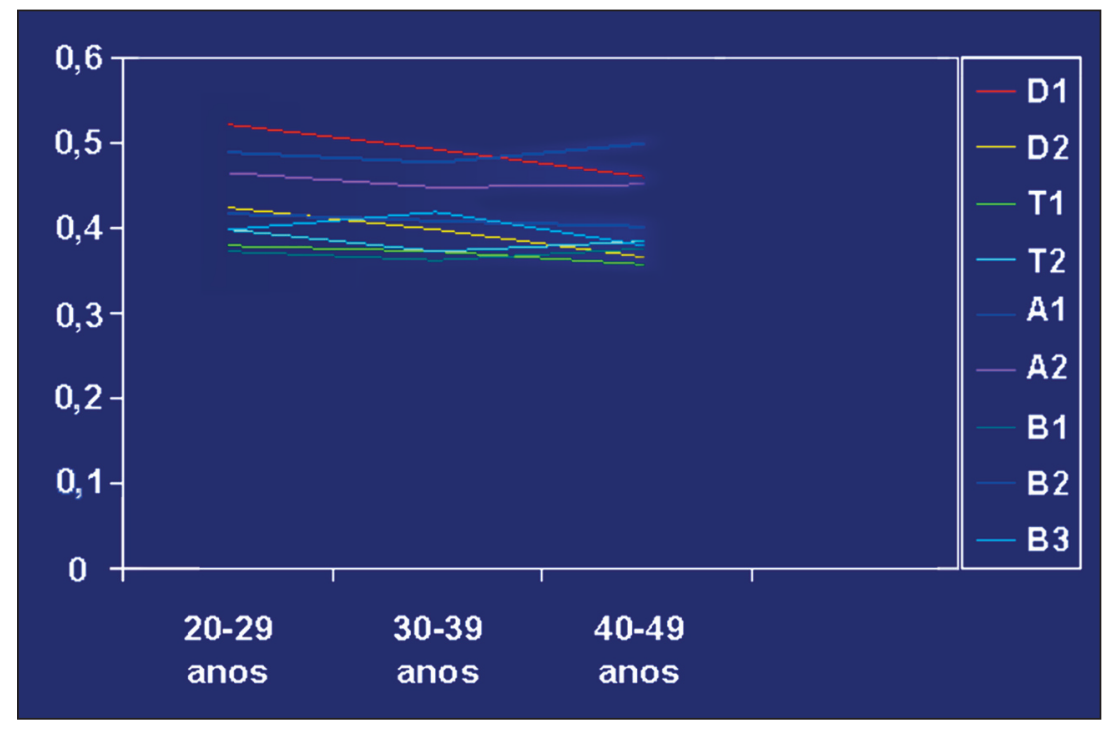

Fig 2. Coherence value for each frequency sub-band at electrode pair F7F8 by age bracket. 
The use of a reference for calculating coherence and also for cartographic/mapping display of spectral parameters, have been the subject of investigation for some years, where some studies have compared the use of several types of reference.

The classic study by Rappelsberger ${ }^{20}$, comparing data obtained through inter-hemispheric and local (adjacent electrodes) coherence analysis, using three types of reference and EEG data simulated by an autoregressive process of the third order, clearly showed that the use of a linked ears reference $(A 1+A 2)$ resulted in the least distortion to the coherence calculation. Based on this information, the option chosen in the present study was the linked ears reference $(A 1+A 2)$, although the equipment software was able to use other reference types.

Statistical analysis of the data obtained in this study using non-parametric methods shows that correlation is elevated amongst all frequency bands, meaning that individuals with high coherence in a particular channel and for a given band, also present high coherence across its entire frequency spectrum. Non-parametric correlation of coherence values between different electrode pairs was also calculated. Again, a high correlation between practically all electrode pairs was observed, indicating that individuals with a high correlation between electroencephalographic signals of particular inter-hemispheric electrode pairs also present high correlation between the other electrode pairs across the whole frequency band analyzed.

A notable finding in the current work was the high inter-hemispheric coherence value found in parietal regions, which may be explained by the anatomic characteristics of the corpus callosum. The greater thickness of the corpus callosum in these regions may be linked to an increased number of interhemispheric fiber connections, leading to a higher inter-hemispheric value in these areas, given the splenium is anatomically related to the parietal and occipital regions ${ }^{21-24}$. Studies employing new magnetic resonance techniques such as tractography, may be able to shed further light on these issues.

In conclusion, the current study shows that age, gender and manual dominance in this age bracket ( 20 to 50 years) do not impact the value obtained for inter-hemispheric coherence, and that all bands have higher coherence values in parietal areas.

\section{REFERENCES}

1. Gotman J. The use computers in analysis and display of EEG and evoked potential. In Daly DD, Pedley TA (Eds). Current practice of clinical electroencephalography. 2.Ed. New York: Lippincott-Raven; 1990:51-83.

2. Cibils D. Análise da coerência na doença de Alzheimer e no envelhecimento normal. In Anghinah R, Luccas FJC (Eds). A neurofisiologia clinica no auxílio diagnóstico das demências. São Paulo: Biosintética, 1999: 63-68.

3. Towle VL, Carder RK, Khorasani L, Linberger D. Electrocorticographic coherence patterns. J Clin Neurophysiol 1999;16:528-547.

4. Nunez P. Electric fields of the brain: the neurophysics of EEG. New York: Oxford University Press, 1981.

5. Nunez PL, Srinivasan R, Westdorp AF, Wijesinghe RS, Tucker DM, Silberstein RB. EEG coherence I: statistics, reference electrode, volume conduction, laplacians, cortical imaging, and interpretation at multiple scales. Electroencephalogr Clin Neurophysiol 1997;103:499-515.

6. Thatcher RW, Krause PJ, Hrybyk M. Cortico-cortical associations and EEG coherence: a two-compartmental model. Electroencephalogr Clin Neurophysiol 1986;64:123-143.

7. Lesser RP. Guidelines Committees of American Electroencephalographic Society. J Clin Neurophysiol 1994;11:9-11.

8. Nuwer MR, Comi G, Emerson R, et al. IFCN standards for digital recording of clinical EEG. Electroencephalograph Clin Neurophysiol 1998;106:259-261

9. Luccas FJ, Braga NI, Fonseca LC, Froch Tengarten ML. Recomendações para o registro e interpretação de mapeamento topográfico do eletrencefalograma (EEG) e potenciais evocados sensoriais (PES) parte I: aspectos gerais. Brazilian J Epilepsy Clin Neurophysiol 1996;2:175-182.

10. Luccas FJ, Anghinah R, Braga NI, et al. Recomendações para o registro/interpretação do mapeamento topográfico do eletroencefalograma e potenciais evocados. Parte II: correlações clínicas. Arq Neuropsiquiatr 1999;57:132-146.

11. Pagano M, Gauvreau K. Coeficientes de correlação de postos de Spearman. In Pagano M, Gauvreau K (Eds). Principios de Bioestatística. São Paulo: Thomson, 2004:357-360.

12. Levin J. Estatística aplicada a ciências humanas. 2.Ed. Tradução de Sergio Francisco Costa. São Paulo: Hamburg, 1987:283-288.

13. Duffy FH, Mcanulty GB, Albert MS. Effects of age upon interhemispheric EEG coherence in normal adults. Neurobiol Aging 1996;17:587-599.

14. Harmony T, Marosi E, Fernandez T, et al. EEG coherences in patients with brain lesions. Int J Neurosci 1994;74:203-226.

15. Thatcher RW, Walker RA, Giudice S. Human cerebral hemispheres develop at different rates and ages. Science 1987;236:1110-1113.

16. Duffy FH, Jones KJ, McAnulty GB, Albert MS. Spectral coherence in normal adults: unrestricted principal components analysis; relation of factors to age, gender, and neuropsychologic data. Clin Electroencefalogr 1995;26:30-46.

17. Anghinah R, Kanda PA, Jorge MS, Lima EE, Pascuzzi L, Melo AC. Estudo da coerência do eletrencefalograma para a banda de freqüência alfa em indivíduos adultos normais e com provável demência do tipo Alzheimer. Arq Neuropsiquiatr 2000;58:272-275.

18. Anghinah R, Caramelli P, Takahashi DY, Nitrini R, Sameshima K. Estudo da coerência do eletrencefalograma na banda de freqüência alfa em indivíduos adultos normais. Arq Neuropsiquiatr 2005;63:83-86.

19. Marosi E, Harmony T, Reyes A, et al. A follow-up study of EEG coherences in children with pedagogical different evaluations. Int J Psychophysiol 1997;25:227-235.

20. Rappelsbersger P. The reference problem and mapping of coherence: a simulation study. Brain Topogr 1989;2:63-72.

21. Hwang SJ, Ji EK, Lee EK, et al. Gender differences in the corpus callosum of neonates. Neuroreport 2004;15:1029-1032.

22. Suganthy J, Raghuram L, Antonisamy B, Vettivel S, Madhavi C, Koshi $R$. Gender and age-related differences in the morphology of the corpus callosum. Clin Anat 2003;16:396-403.

23. Takeda S, Hirashima Y, Ikeda H, Yamamoto H, Sugino M, Endo S. Determination of índices of the corpus callosum associated with normal aging in Japanese individuals. Neuroradiology 2003;45:513-518.

24. Laissy JP, Patrux B, Duchateau C, et al. Midsagittal MR measurements of the corpus callosum in healthy subjects and diseased patients: a prospective survey. AJNR Am J Neuroradiol. 1993;14:145-154. 